\title{
Crime and prostitution zones
}

Am. Econ. J. Econ. Policy 9, 28-63 (2017)

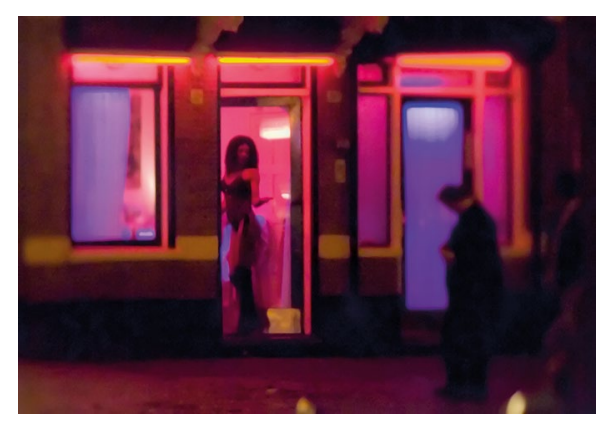

Credit: Kevin Steele / Aurora / Getty

Despite its colloquial designation as 'the oldest profession', prostitution is widely illegal and the debate surrounding legalization can be polarizing. While arguments in support of legalization are manifold, ranging from the pragmatic to the ideological, the empirical evidence about the effects of regulation on crime is scant, often due to insufficient data. The heightened vulnerability of sex workers makes obtaining this evidence a priority.

In a recent paper, Stephen Kastoryano and colleagues use the opening and closing of tippelzones - designated legal street prostitution areas - in nine Dutch cities between 1994 and 2011 as a natural experiment to analyse the relationship between the regulation of sex work and crime. The authors find that opening a tippelzone decreases reported sexual abuse and rape by 30 to $40 \%$, but only in the first two years. A possible explanation for the return to baseline levels is the displacement of unlicensed workers, though changes in police monitoring and other factors may also be at play. Cities that enforced licensing also reported a $25 \%$ reduction in drug-related crime.

While these results suggest that the regulation of sex work may be an effective measure for reducing sex crimes, at least in the short term, it remains for future work to untangle the underlying causes of this reduction as well as cultural and other potential effects of regulation.

Sara Constantino

Published online: 30 November 2017

https://doi.org/10.1038/s41562-017-0269-0 